\title{
Dose Water Extract of Cinnamon (Cinnamomum Zeylanicum) Exhibits Anti-Diabetic Properties in Cultured 3T3-L1 Adipocytes: A Concurrent Assessment of Adipogenesis, Lipolysis and Glucose Uptakes
}

\author{
Nuraniza Azahari ${ }^{1}$, Muhammad Muzaffar Ali Khan Khattak, 1,2,3, ${ }^{*}$ Muhammad Taher, ${ }^{2,3,4}$, \\ Solachuddin Jauhari Arief Ichwan ${ }^{5}$ \\ ${ }^{1}$ Department of Nutrition Sciences, Kulliyyah of Allied Health Sciences, International Islamic University Malaysia (IIUM), Jalan \\ Sultan Ahmed Shah, Bandar Indera Mahkota Kuantan, 25200 Pahang Darul Makmur, MALAYSIA \\ ${ }^{2}$ Non Communicable Diseases Research Unit, Kulliyyah of Medicine, International Islamic University Malaysia (IIUM), Jalan Sultan \\ Ahmad Shah, Bandar Indera Mahkota, 25200 Kuantan, Pahang Darul Makmur, MALAYSIA \\ ${ }^{3}$ International Institute for Halal Research and Training (INHART), E5 2-2, Level 2, Block E5, Kulliyyah of Engineering, International \\ Islamic University Malaysia (IIUM), P.O. Box 10 Kuala Lumpur, MALAYSIA \\ ${ }^{4}$ Department of Pharmaceutical Technology, Kulliyyah of Pharmacy, International Islamic University Malaysia (IIUM), Jalan Sultan \\ Ahmad Shah, Bandar Indera Mahkota, 25200 Kuantan, Pahang Darul Makmur, MALAYSIA \\ ${ }^{5}$ Department of Basic Medical Sciences, Kulliyyah of Dentistry, International Islamic University Malaysia (IIUM), Jalan Sultan \\ Ahmad Shah, Bandar Indera Mahkota, 25200 Kuantan, Pahang Darul Makmur, MALAYSIA \\ *Corresponding author: mkbiol@yahoo.com
}

Received September 26, 2014; Revised October 05, 2014; Accepted October 13, 2014

\begin{abstract}
Cinnamon is a common spice which is widely advocated for its efficacy controlling of hyperglycemia. However, the mechanism of action has yet to be established for the effect on the blood glucose concentration. Cinnamon was extracted with water and induced to cell line namely 3T3-L1 preadipocyte (American Type cell Culture Collection). The cell proliferation, differentiation (adipogenesis) and glucose uptake activity were assessed by measuring the uptake of radio-labelled glucose. Furthermore, for comparison glucose oxidase assay was also performed by using Glucose Assay Kit (Sigma-Aldrich, Inc). The collected data was statistically analysed using SPSS version 12.0 for any possible differences. This study revealed that there was a significant $(\mathrm{P}<0.01)$ increase the activity/adipogenesis. This increase activity was accompanied by significant $(\mathrm{P}<0.01)$ increase in the glucose uptake and reduced catalytic activity of lipids (lipolysis). The finding reveals that $C$. Zeylanicum extract has similar effect to that of insulin activity. The present study suggests that the cinnamon enhances glucose uptakes, reduces the lipid breakdown and resembles insulin activity.
\end{abstract}

Keywords: cinnamon, 3T3-L1 adipocytes, adipogenesis, glucose uptake, glucose oxidase

Cite This Article: Nuraniza Azahari, Muhammad Muzaffar Ali Khan Khattak, Muhammad Taher, and Solachuddin Jauhari Arief Ichwan, "Dose Water Extract of Cinnamon (Cinnamomum Zeylanicum) Exhibits AntiDiabetic Properties in Cultured 3T3-L1 Adipocytes: A Concurrent Assessment of Adipogenesis, Lipolysis and Glucose Uptakes.” Journal of Food and Nutrition Research, vol. 2, no. 11 (2014): 764-769. doi: 10.12691/jfnr-2-11-1.

\section{Introduction}

The prevalence of diabetes and obesity have been increasing among the various communities of the world including Malaysia. Its rapid increase in the global prevalence is a greater concern to the countries and global communities. According to [1], it is estimated that the world prevalence of diabetes among adults aged $20-79$ years was affected 285 million people worldwide in 2010 and will increase to 439 million by the year 2030. Within these 20 years, there will be a $69 \%$ increase in numbers of adults with diabetes in developing countries and there will be a $20 \%$ increase in the developed countries. The prevalence of diabetes reported for Malaysia in National Health and Morbidity Surveys I, II, \& III (NHMS) has been reported to be from $6.30-11.70 \%[2,3,4]$. The incidence is expected to increase to $13.3 \%$ in the year 2030. In the NHMS III the Indians had the highest prevalence of diabetes which is $19.9 \%$ followed by Malays 11.9 and Chinese $11.4 \%$ [2,3,4,5]. This exponential increase in diabetes is extremely alarming for the country and for the families having patient(s) suffering from diabetes. This is not only increases the cost of the treatment to the family but also incurred substantial losses to the country. Therefore, it is important to explore non pharmacological regimens that are non-invasive and with least health risk and financial burden to the patients. Since ancient time, plants have been used almost in all cultures 
as sources of treatment and prevention. It has been estimated that about $80-85 \%$ of population in developed and developing countries depend on traditional and complementary medicine for their primary health care needs. This involves the use of plant extracts or their active compounds as a major part of traditional use $[6,7,8]$. This study aimed to elucidate the effect of a common spice namely Cinnamomum Zeylanicum for the potential anti-diabetic properties (based on traditional uses) via in vitro model. The genus Cinnamomum belongs to the family Lauraceae which comprises about 250 species and distributed in India, China, Sri Lanka and Australia. C. Zeylanicum is the source of cinnamon bark and leaf oils and a local tree of Sri Lanka. Cinnamomum leaves and bark are used extensively as spices in food or to produce essential oils [9]. There are more than 80 compounds identified from different parts of cinnamon. Major components of volatile oils from stem bark and root bark are cinnamaldehyde and camphor respectively that are found to have antioxidant, antimicrobial and anti-diabetic effects [10]. The volatile oils of cinnamon have an effect against renal damage by decreasing fasting blood glucose levels in early stage of diabetic nephropathy in a dosedependent manner [11]. In Malaysia, cinnamon bark is widely used as a spice in cooking. It has been reported to have remarkable pharmacological effects in the treatment of type 2 diabetes mellitus and insulin resistance. It has been proved that a compound known as cinnamtannin B1 isolated from $C$. zeylanicum have a positive effect in in vitro model [12]. According to another study, cinnamon may improve blood glucose and lipid profile in people with type 2 diabetes [13]. Adipocytes are used as a research model in this type of studies because of its speciality to play a major role in the energy homeostasis of an organism. Major functions of adipocytes are to synthesize and store triglycerides at the times of excess caloric intakes and to mobilize these stores when caloric intake is low. Adipocytes are important tissues sensitive to insulin, where it causes glucose uptake and its incorporation into fat as glycerol, and inhibits the lipolysis of triglycerides [14]. Since the consumption of this spice is quite common as a part of food and traditional uses it is worthwhile to further explore its efficacy for diabetes using C. Zeylanicum crude water extracts in cultured 3T3L1 adipocytes.

\section{Materials and Methods}

The cell line, namely 3T3-L1 preadipocyte (derived from mouse embryonic fibroblast) was purchased from American Type Culture Collection (Manassas, VA). Dried and powdered $C$. Zeylanicum was extracted and freeze dried. The crude extracts were weighed and stored at $80^{\circ} \mathrm{C}$ for further analysis. The 3T3-L1 preadipocytes were grown in Dulbecco's Medium Eagle Medium (DMEM) and supplemented with $10 \%$ fetal bovine serum (FBS) and $1 \%$ penicillin and $1 \%$ streptomycin.

\subsection{Cells Viability}

Cell viability was assessed by using 3-(4, 5dimethylthiazol-2-yl)-2, 5-diphenyltetrazolium bromide (MTT) assay as described previously with slight modification by [15]. Treated cells were incubated for one day at $37^{\circ} \mathrm{C}$ in humidified $5 \% \mathrm{CO}_{2}$ atmosphere. The adherent cells were washed two times with Phosphate buffered saline (PBS). Then, $20 \mu \mathrm{l}$ of MTT stock solution (5 $\mathrm{mg} / \mathrm{ml}$ ) was added to each well and the plates were further incubated for 4 hours at $37^{\circ} \mathrm{C}$. Then, $100 \mu \mathrm{l}$ of DMSO was added to each well. Cells were left for one hour and the absorbance was measured at a wavelength of $570 \mathrm{~nm}$ and reference wavelength $630 \mathrm{~nm}$ with a micro plate reader (Dynatech MR5000).

\subsection{Maintenance Cell Culture}

The 3T3-L1 cells were cultured and maintained as previously described by [12]. Cells were seeded and differentiated at 3 x 104 in 96-well plate containing $0.1 \mathrm{ml}$ $(100 \mu \mathrm{l})$ medium. Induction of differentiation was performed at day- 2 post confluence. Three days after the induction, the cells were treated with insulin alone for another two days. Then, five days after induction, medium was changed in every two days until day-10.

\subsection{Adipogenesis (Lipid Synthesis) and Lipolysis (Lipid Breakdown)}

The visible accumulation of lipid droplets was monitored with a microscope. At day 11 after induction, medium removed and $75 \mu$ l of lipid droplets assay fixative were added to each well and incubated for 15 minutes. After that, the wells were washed with $100 \mu$ l of wash solution twice for five minutes each and allowed to dry completely. Then, $75 \mu$ l of Oil Red O working solution was added to all wells and incubated for 20 minutes. After that, all Oil Red $\mathrm{O}$ solution was removed and the cells were washed with distilled water several times. This was followed by washing the wells with $100 \mu$ l of washing solution twice for 5 minutes each. At this point, microscope images were taken to visualize pink to red oil droplets staining in differentiated cells. Lastly, $100 \mu \mathrm{l}$ of dye extraction solution was added to each well. Cells were gently mixed for 15 to 30 minutes and the absorbance was measured at 490-520 nm with ultraviolet spectrophotometer.

\subsection{Glucose Uptake by Radio-labelled Glucose Assay}

Glucose uptake activity was analyzed by measuring the uptake of radiolabelled glucose. This was performed based upon previously described methods with modification by [16]. Differentiated cells were washed twice with serumfree DMEM and incubated in $1 \mathrm{ml} /$ well serum-free DMEM for 3 hours at $37^{\circ} \mathrm{C}$. Then, washed three times with Krebs-Ringer HEPES (KRPH) buffer (118 mM NaCl, $5 \mathrm{mM} \mathrm{KCl}, 1.3 \mathrm{mM}$ CaCl2, $1.2 \mathrm{mM}$ MgSO4, $1.2 \mathrm{mM}$ KH2PO4 and $30 \mathrm{mM}$ HEPES, $\mathrm{pH}$ 7.4) and incubated with $1 \mathrm{ml} /$ well of $\mathrm{KRPH}$ buffer for 30 minutes at $37^{\circ} \mathrm{C}$. Cinnamon extracts, metformin, and sodium orthovanadate were added 30 minutes prior to the addition of 2-deoxy-D[1,2-3H] -glucose. For the measurement, 2-deoxyglucose $(0.001 \mathrm{mM})$ was used together with the radiolabeled tracer, 2-deoxy-D-[1,2-3H]-glucose $(0.037 \mathrm{MBq})$ to give a concentration of $0.2 \mathrm{mM}(0.5 \mathrm{mCi} / \mathrm{mmol})$ yielding an activity of $0.1 \mu \mathrm{Ci} / \mathrm{ml}$. After 60 minutes at $37^{\circ} \mathrm{C}$, glucose uptake was terminated by washing the cells three times with $3 \mathrm{ml} /$ well of ice-cold phosphate-buffered saline $(\mathrm{pH}$ 
7.4). Cells were then washed and lysed with $0.7 \mathrm{ml}$ of $1 \%$ Triton X-100 for 40 minutes at $37^{\circ} \mathrm{C}$. Samples from each lysates were counted using a liquid scintillation counter (Packard Tricarb 2700 TR/SL liquid scintillation analyzer, Packard Instrument Co).

\subsection{Glucose Concentration by Glucose Oxidase Assay}

The glucose oxidase assay was performed by using Glucose Assay Kit (Sigma-Aldrich, Inc). The 3T3-L1 adipocytes were cultured in 96 well plates until reaching $90 \%$ confluent. The medium was then removed and its glucose concentration was determined. The reactions started by adding $100 \mu \mathrm{l}$ of glucose assay reagent to $50 \mu \mathrm{l}$ mediums and mixed gently. The wells were allowed to mix for a 30 - 60 second interval between additions of glucose assay reagent to each subsequent well. Then, each well was treated with extracts exactly for 30 minutes at $37^{\circ} \mathrm{C}$. Then, the reactions were stopped at $30-60$ second intervals by adding $100 \mu \mathrm{l}$ of $12 \mathrm{~N} \mathrm{H}_{2} \mathrm{SO}_{4}$ into each well and were carefully mixed thoroughly. The absorbance was measured at $540 \mathrm{~nm}$ using a UV spectrophotometer.

\subsection{Statistical Analysis}

The collected data were compiled and statistically analyzed using SPSS (Version 15.0). One-way analysis of variance (ANOVA) was used wherever appropriate. The data were considered statistically different at 95\% confidence interval. The statistical differences in the means were ascertained by using Turkey's post-hoc test.

\section{Results}

As mentioned earlier, the effect of water extract of $C$. Zeylanicum was evaluated on the various parameters in cultured 3T3-L1 preadipocyte using as a research model in this study. In general the yield of the water extract was 2.94 gram $/ 50 \mathrm{~g}$ (5.90\%) of powdered cinnamon bark. The effects are shown in the following section of this article.

\subsection{Effect on Cell Proliferation and Viability}

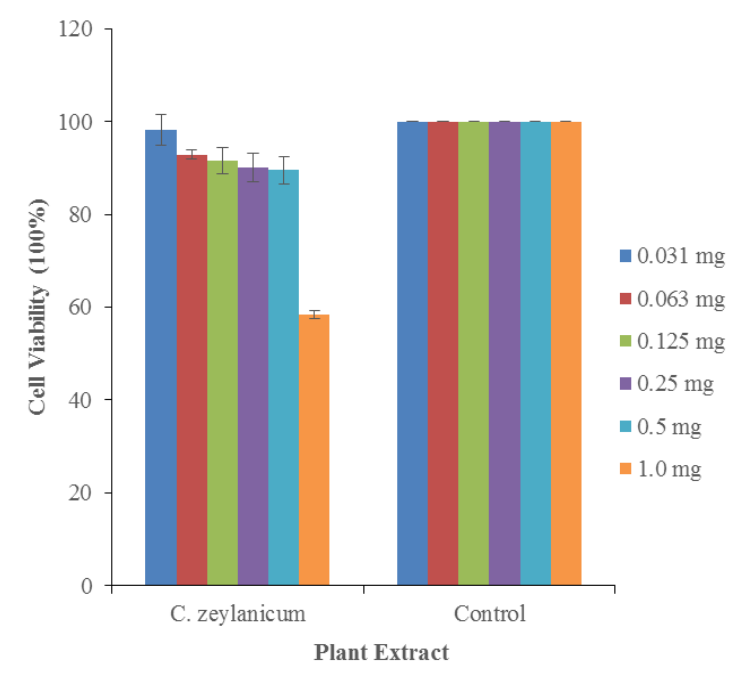

Figure 1. Effect of C. Zeylanicum water extract on the adipose cells (3T3-L1 adipocytes) viability at a concentration ranges from 0.031-1.00 mg assessed by using 3-(4,5-dimethylthiazol-2-yl)-2, 5diphenyltetrazolium bromide (MTT) assay
The concentration of $0.25 \mathrm{mg} / \mathrm{ml}$ extracts resulted in the maximum cell growth with approximately $90 \%$ of viability, after applying for 48 hours. When the doses were increased correspondingly the cells viability decreased and there was a least viability at a dose of 1 $\mathrm{mg} / \mathrm{ml}$. In the present study, the effective concentration of extracts was $0.25 \mathrm{mg} / \mathrm{ml}$ as shown in the Figure 1 . Thus, the MTT assay indicates that the adipocytes tolerated the extracts well at a concentration of $0.25 \mathrm{mg} / \mathrm{ml}$. Therefore, the concentration of $0.25 \mathrm{mg} / \mathrm{ml}$ was used in the various subsequent assays since adipocytes exhibited optimal tolerances for it.

\subsection{Effect on adipogenesis}

After day 11, preadipocyte differentiation was terminated and stained with Oil Red $O$ which allowed visualizing the lipid droplets in all induced cells Figure 3 and 4 . The red areas show the lipid droplets in the adipocytes. There was a significant $(\mathrm{p}<0.01)$ increases in adipogenesis (lipid synthesis) of cells treated with insulin and $C$. zeylanicum extract compared to the control. The results are expressed in the absorbance values. Higher absorbance shows more formation of lipid droplets and effectiveness to induce the differentiation in preadipocyte to adipocytes. The present study, indicated that insulin gave the highest lipid droplets formation followed by $C$. zeylanicum extracts compared to the control.

\subsection{Effect on Adipolysis}

The adipolysis was assessed quantitatively in vitro by making use of glycerol release of the differentiated 3T3L1 adipocytes into the culture medium. This was performed using the glycerol release assay kit. The increase release of glycerol into the medium show that there was significant $(\mathrm{p}<0.01)$ increase in adipolytic activities in the adipocytes treated with isoproterenol compared to control. However, insulin and C. Zeylanicum extract produced a moderate release of glycerol (Figure 5).

\subsection{Effect on Glucose Uptake}

Interestingly, when the cells were incubated in a medium containing 2-deoxy-D-[1,2- $\left.{ }^{3} \mathrm{H}\right]$-glucose in combination with 2-deoxyglucose, there were significant $(\mathrm{p}<0.01)$ increases in glucose uptake activity in cells treated both with Sodium Orthovanadate and $C$. zeylanicum extracts compared to control as indicated in the Figure 6.

\subsection{Effect on Glucose Oxidase}

The significant $(\mathrm{p}<0.01)$ reduced concentration of glucose in the medium is indicative of an increased consumption of glucose therefore, the lowered glucose concentration was observed in the supernatant. From the results, it is evident that insulin showed higher $(\mathrm{p}<0.01)$ consumption of glucose in the medium followed by cinnamon as compared to counterpart control (Figure 7).

\section{Discussions}

The results of the present may aid to clinical uses of cinnamon for the purposes of type 2 diabetes mellitus and 
along with this may help in the understanding of the underlying mechanistic puzzle of its effect on blood glucose and lipid concentrations. The uses of the cinnamon in the past and presently well documented in delicacies, medicinal or herbal products in most cultures $[17,18,19]$. The folklores claim on the use of the plants eventually led to the extraction of their active components. In order to further this concept in this study, the extraction was performed using water as a solvent under constant temperature of $60^{\circ} \mathrm{C}$ for 24 hours in an incubator shaker. This procedure actually mimics the preparation of hot tea where the leaves of tea are left for a certain period of time in hot water in order to extract their polar constituents. Thus, the crude water extracts of C. Zeylanicum was successfully prepared with a yield of 5.9\%.

The observed effect of the extracts on adipogenesis in adipocytes (Figure 2) is of clinically importance for glucose homeostasis and energy storage. Insulin gave the highest lipid droplet formation. This was similar with previous study which revealed that insulin act as an essential regulator of the differentiation of 3T3-Ll adipocytes and accelerates the differentiation process [20,21,22]. During differentiation, 3T3-L1 cells experience a 20 -fold increase in the number of insulin receptors and acquire the ability to utilize glucose in response to insulin [23]. C. Zeylanicum extracts showed significantly increased adipocytes differentiation compared to the control which is indicated by the accumulation of lipid droplets (Figure 4).

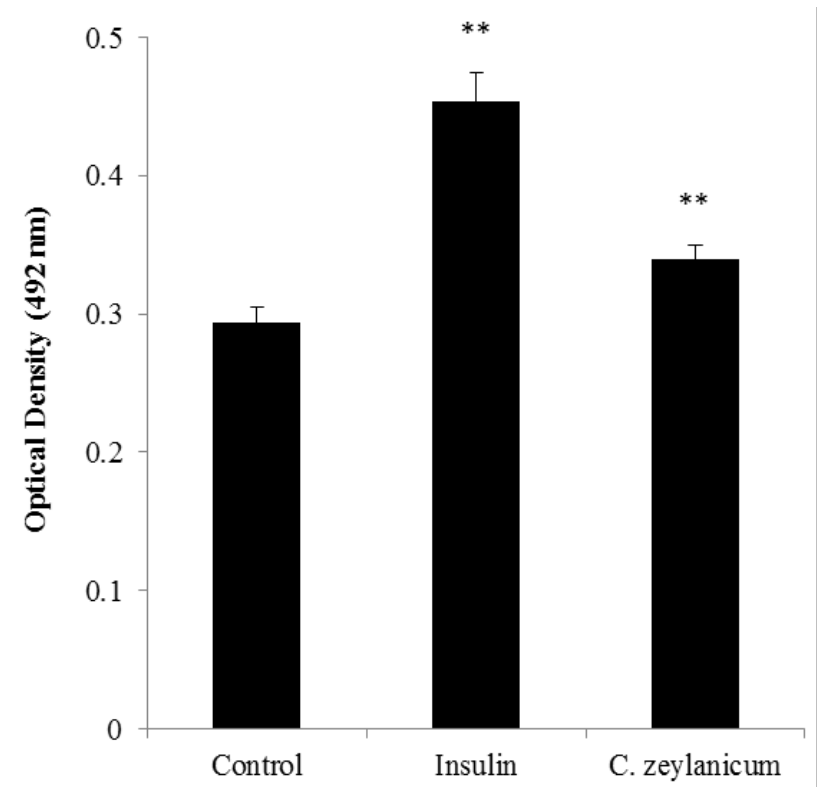

Figure 2. The effect of C. Zeylanicum extract on the adipogenesis in 3T3-L1 adipocytes. Data are means \pm S.D. of three observations. Control and treated cells with the extract $(0.25 \mathrm{mg} / \mathrm{ml})$ show significant $(\mathrm{P}<0.01)$ difference using Turkey's post hoc test. $* *=\mathrm{P}<0.01$

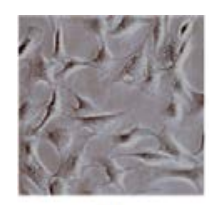

(A)

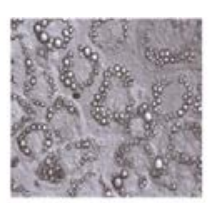

(B)

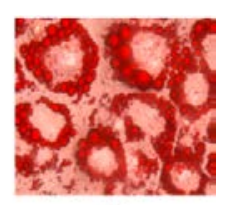

(C)
Figure 3. Morphology of 3T3-L1 cells. Show the preadipocyte at day-3, B show mature adipocytes at day-11 after induction with an inducer cocktail and $\mathrm{C}$ show 3T3-L1 cells after oil red $O$ staining. The differentiated cells show characteristics of lipid droplets

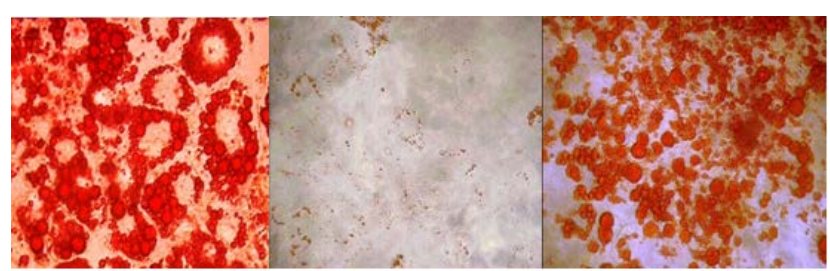

Figure 4. Effect of extracts on adipocytes differentiation after Oil Red $O$ staining at magnification $20 \mathrm{X}$ and the red is area of lipid droplets. D show adipocytes containing Insulin, E show adipocytes without treatment and $\mathrm{F}$ show adipocyte containing $C$. Zeylanicum extract

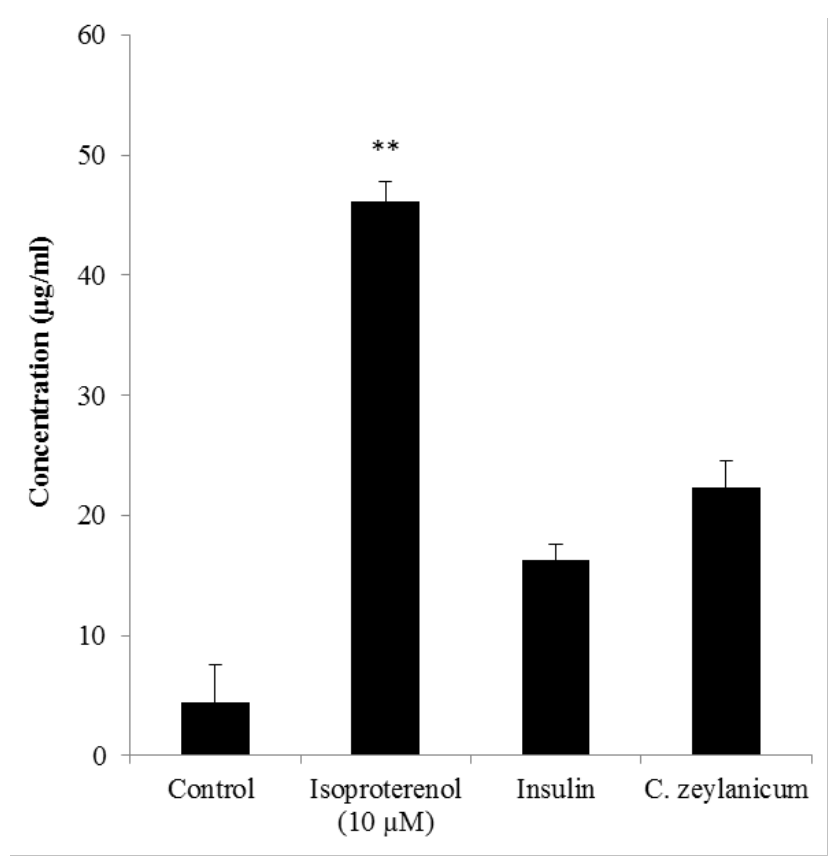

Figure 5. The effect of $C$. Zeylanicum extract on glycerol release in 3T3L1 adipocytes (adipolysis). Data are means \pm S.D of three observations, expressed as glycerol concentration $(\mu \mathrm{g} / \mathrm{ml})$. Control and treated cells with the extract $(0.25 \mathrm{mg} / \mathrm{ml})$ show significant $(\mathrm{P}<0.01)$ difference using Turkey's post hoc test. $* *=\mathrm{P}<0.01$

This finding is also in agreement with a previous study that was reported [24] which shows that induction of adipocyte differentiation by cinnamtannin B1, an active compound found in C. Zeylanicum water extract gave similar effects as insulin activity in adipogenesis. Another study [25] shows a consistent result of this study in which it was observed that replacing insulin with cinnamon extract results in full differentiation of the adipocytes. This might be due to the presence of polyphenols which is the compound from water extract of cinnamon. Similarly, the observed effects of the extracts on the adipolysis in the adipocytes (Figure 5) shows that treating the cells with $100 \mu \mathrm{M}$ isoproterenol gave the highest concentration of glycerol release. This is consistent with previous studies which shows that there are several compounds to be involved in stimulation of adipolysis in differentiation of 3T3-L1 and primary human adipocytes which include isoproterenol and tumor necrosis factor- $\alpha$ (TNF- $\alpha$ ) [26]. This observation is was similar to with a previous study which showed that treating adipocytes with isoproterenol markedly increases the glycerol release of the adipocytes whereas insulin suppresses this release [27]. However, insulin and C. Zeylanicum extract showed a decreased in adipolysis activity (Figure 5). 


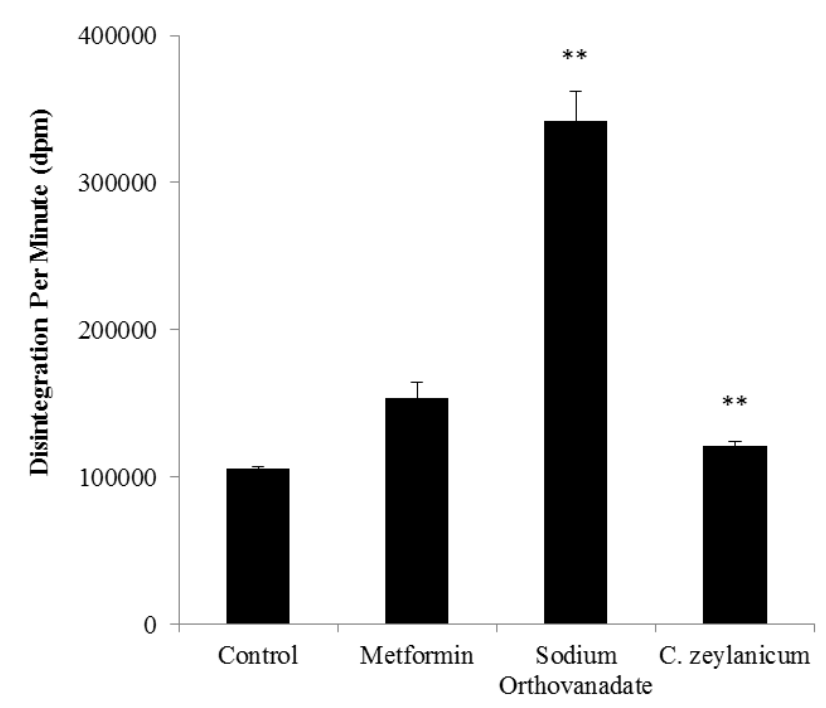

Figure 6. The effect of $C$. Zeylanicum extract on glucose uptake in 3T3L1 adipocytes. Data are means \pm S.D. of three observations, expressed as disintegration per minute (DPM). Control and treated cells with the extract $(0.25 \mathrm{mg} / \mathrm{ml})$ show significant $(\mathrm{P}<0.01)$ difference using Turkey's post hoc test. $* *=\mathrm{P}<0.01$

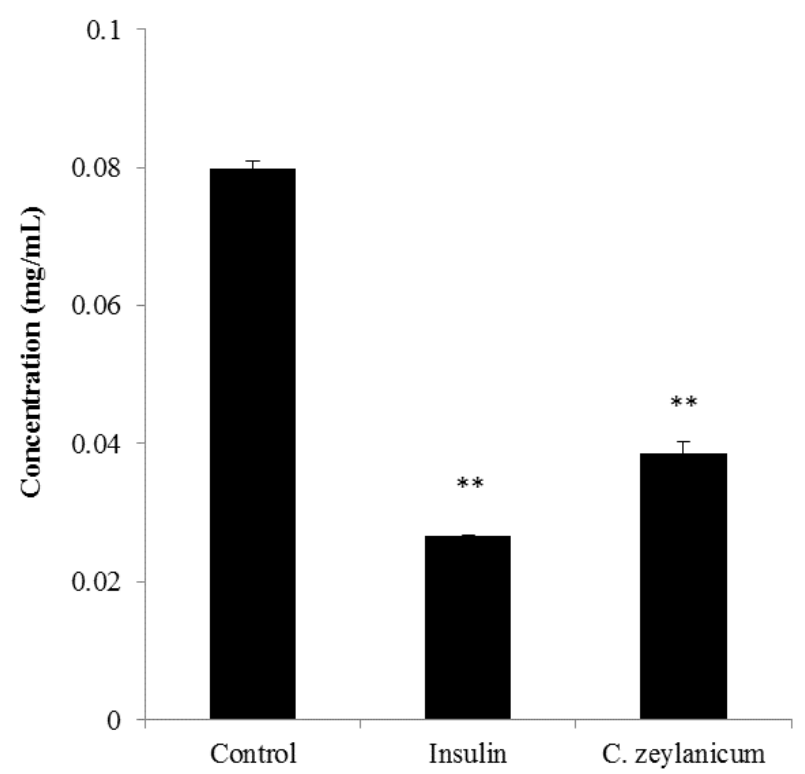

Figure 7. The effect of $C$. Zeylanicum extract on glucose oxidase assay in 3T3-L1 adipocytes. Data are means \pm S.D. of three observations, expressed as glucose concentration $(\mathrm{mg} / \mathrm{ml})$. Control and treated cells with the extract $(0.25 \mathrm{mg} / \mathrm{ml})$ show significant $(\mathrm{P}<0.01)$ difference using Turkey's post hoc test. ${ }^{* *}=\mathrm{P}<0.01$

The observed effect of the extracts on glucose uptake radio-labelled assay (Figure 6) and glucose oxidase assay (Figure 7) showed increased activity when the adipocytes are treated with C. Zeylanicum. This increased activity previously reported [28]. The compounds such as flavonoids, phenolic acids and tannins have been implicated in hypoglycaemic activity and these compounds have been found in extracts of C. Zeylanicum which may be in partially responsible for the observed upregulatory activities of glucose. In this study, glucose uptake activity of the extracts was compared with metformin and sodium orthovanadate. The findings showed that sodium orthovanadate significantly elevate glucose uptake in adipocytes but not metformin. There was an increased glucose uptake activity for Sodium Orthovanate compared to metformin and control by 2.2- and 3.2-fold respectively. Sodium orthovanadate is also known as insulin mimetic agents and displays insulin-like effects. This finding support the idea that vanadate stimulates the rate of 2-deoxyglucose uptake to a similar extent as insulin does in the adipocytes. These effects suggested that vanadate induced the recruitment of Glut-4 in the plasma similar to insulin [29]. Metformin has been shown to increase glucose uptake in human adipocytes in a dose and time dependent manner in a study performed [30]. The study showed an increase cellular glucose uptake after 24 and 48 hour treatment with metformin, but does not increase glucose uptake with just 3 hours incubation time. Furthermore, incubation with 0.001 and $0.1 \mathrm{mM}$ metformin also does not potentiate the glucose uptake compared to 1 and $10 \mathrm{mM}$ metformin [30].

\section{Conclusions}

There is a concomitant relationship between adipogenesis, adipolysis and glucose uptake/oxidase activity when the adipocytes are treated with cinnamon. These activities are vital for the explanation of adipose tissue functioning in relation to diabetes and associated metabolic functions. The hypoglycaemic effect is due to increased adipogenesis and glucose uptake/oxidase enzyme with concurrent inhibition of adipolysis. This study suggests that cinnamon extract possess insulinmimicking effects in the adipocytes.

\section{Acknowledgements}

This study was supported by the Research Management Centre, International Islamic University Malaysia (IIUM) Grant number EDW B0906-316. The authors would like to thankfully acknowledge the Research Management Centre, International Islamic University Malaysia (IIUM) Kuala Lumpur 5072- Malaysia, for the research grant.

\section{References}

[1] Shaw, J.E, Sicree, R,A, Zimmet, P.Z, “Global estimates of the prevalence of diabetes for 2010 and 2030”, Diabetes Research and Clinical Practice, 87 (1): 4-14, 2010.

[2] National Health Morbidity Survey (2006). Diabetes. Institute for Public Health, Ministry of Health, Malaysia.

[3] National Health Morbidity Survey (1986-1987). Diabetes Mellitus. Volume 4. Institute for Public Health, Ministry of Health, Malaysia.

[4] National Health Morbidity Survey (1996). Diabetes. Volume 9. Institute for Public Health, Ministry of Health, Malaysia.

[5] Letchuman, G, Wan Nazaimoon, W, Wan Mohamad, W, Chandran, L, Tee, G, Jamaiyah, H, "Prevalence of Diabetes in the Malaysian National Health Morbidity Survey III (2006),” Medical Journal Malaysia, 65 (3): 180-6, 2010.

[6] Elujoba, A.A, Odeleye, O, Ogunyemi, C, "Review-Traditional medicine development for medical and dental primary health care delivery system in Africa," African Journal of Traditional, Complementary and Alternative Medicines, 2 (1): 46- 612005.

[7] Muthu, C, Ayyanar, M, Raja, N, and Ignacimuthu, S, "Medicinal plants used by traditional healers in Kancheepuram District of Tamil Nadu, India,” Journal of Ethnobiology and Ethnomedicine, 2: 43, 2006.

[8] Tomlinson, T.R, Akerele, O, Medicinal plants: their role in health and biodiversity, University of Philadelphia Press, Michigan, 1998.

[9] Jayaprakasha, G.K, Rao, L.J.M, Sakariah, K.K, "Volatile constituents from Cinnamomum zeylanicum fruit stalks and their 
antioxidant activities,” Journal of agricultural and food chemistry, 51 (15): 4344-8, 2003.

[10] Jayaprakasha, G, Rao, L.J.M, "Chemistry, biogenesis, and biological activities of Cinnamomum zeylanicum,” Critical reviews in food science and nutrition, 51 (6): 547-62, Jul. 2011.

[11] Mishra, A, Bhatti, R, Singh, A, Singh, I.M.P, “Ameliorative effec of the cinnamon oil from Cinnamomum zeylanicum upon early stage diabetic nephropathy,” Planta medica, 76 (5): 412-7, Mar. 2010.

[12] Taher, M., Isolation and in vitro antidiabetic properties of a proanthocyanidin from Cinnamomum zeylanicum. PhD thesis, Universiti Teknologi Malaysia, Faculty of Chemical and Natura Resources Engineering, 2005.

[13] Khan, A, Safdar, M, Khan, M.M.A.K, Khattak, K.N, Anderson, R.A, "Cinnamon improves glucose and lipids of people with type 2 diabetes,” Diabetes care, 26 (12): 3215-3218, Dec. 2003.

[14] Wu, Z, Xie, Y, Morrison, R.F, Buche, N, Farmer, S.R, "PPAR gamma induces the insulin-dependent glucose transporter GLUT4 in the absence of C/EBPalpha during the conversion of 3T3 fibroblasts into adipocytes," Journal of Clinical Investigation, 101: 22, 1998.

[15] Mosmann, T, "Rapid colorimetric assay for cellular growth and survival: application to proliferation and cytotoxicity assays," Journal of Immunological Methods, 65 (1-2): 55-63, Dec. 1983.

[16] Roffey, B, Atwal, A, Kubow, S, "Cinnamon water extracts increase glucose uptake but inhibit adiponectin secretion in 3T3L1 adipose cells," Molecular nutrition and food research, 50 (8): 739-45, Aug. 2006.

[17] Bailey, C.J, and Day, C, "Traditional plant medicines as treatments for diabetes,” Diabetes care, 12 (8): 553-564, Sep. 1989.

[18] Jia, W, Gao, W, Tang, L, "Antidiabetic herbal drugs officially approved in China," Phytotherapy Research, 17: 1127-1134, 2003.

[19] Lau, C.H, Chan, C.M, Chan, Y.W, Lau, K.M, Lau, T.W, Lam, F.C, "In vitro antidiabetic activities of five medicinal herbs used in Chinese medicinal formulae,” Phytotherapy Research, 22 (10): 1384-1388, Oct. 2008.

[20] Smith, P.J, Wise, Berkowitz, R, Wan, C, Rubin, C, “Insulin-like growth factor-I is an essential regulator of the differentiation of 3T3-L1 adipocytes,” Journal of Biological Chemistry, 263 (19): 9402-9408, Jul. 1988.
[21] Kletzien, R.F, Clarke, S.D, Ulrich, R.G, "Enhancement of adipocyte differentiation by an insulin-sensitizing agent," Molecular pharmacology, 41 (2), 393-398, 1992.

[22] Guller, S, Corin, R.E, Mynarcik, D.C, London, B.M, Sonenberg, M, "Role of insulin in growth hormone-stimulated 3T3 cell adipogenesis,” Endocrinology, 122 (5): 2084-2089, Jul. 2013.

[23] Frost, S.C, Lane, M.D, "Evidence for the involvement of vicinal sulfhydryl groups in insulin-activated hexose transport by 3T3-L1 adipocytes,” Journal Biolological Chemistry, 260 (5): 2646-52, Mar. 1985.

[24] Taher, M, Abdul, M.F.A, Sarmidi, M.R, "Cinnamtannin B1 activity on adipocytes formation," The Medical Journal of Malaysia, 59: 97-98, May. 2004

[25] Cao, H, Graves, D.J, Anderson, R.A, “Cinnamon extract regulates glucose transporter and insulin-signaling gene expression in mouse adipocytes,” Phytomedicine, 17 (13): 1027-32, Nov. 2010.

[26] Zhang, H.H, Souza, S.C, Muliro, K.V, Kraemer, F.B, Obin, M.S and Greenberg, A.S, "Lipase-selective functional domains of perilipin A differentially regulate constitutive and protein kinase A-stimulated lipolysis,” Journal of Biological Chemistry, 278 (51) 51535-42, Dec. 2003.

[27] Hattori, K, Sukenobu, N, Sasaki, T, Takasuga, S, Hayashi, T, Kasai, R, "Activation of insulin receptors by lagerstroemin," Journal of Pharmacological Sciences, 93 (1): 69-73, Sep. 2003.

[28] Roffey, B, Atwal, A, Kubow, S, "Cinnamon water extracts increase glucose uptake but inhibit adiponectin secretion in 3T3-L1 adipose cells," Molecular nutrition \& food research, 50 (8): 739-45, Aug. 2006

[29] Paquet MR, Romanek R., Sargeant RJ (1992). Vanadate induces the recruitment of glut-4 glucose transporter to the plasma membrane of rat adipocytes. Molecular and Cellular Biochemistry, 109: $149-155$.

[30] Grisouard, J, Timper, K, Radimerski, T.M, Frey, D.M, Peterli, R, Kola, B, "Mechanisms of metformin action on glucose transport and metabolism in human adipocytes," Biochemical Pharmacology, 80 (11): 1736-45, Dec. 2010 